Grand Valley State University

ScholarWorks@GVSU

2014

\title{
Microgeographic Population Genetic Structure of Baylisascaris Procyonis (Nematoda: Ascaroidae) in Western Michigan Indicates the Grand River is a Barrier to Gene Flow
}

\author{
Christina A. Sarkissian \\ Grand Valley State University, sarkissc@mail.gvsu.edu \\ Douglas H. Graham \\ Grand Valley State University, grahamdo@gvsu.edu
}

Follow this and additional works at: https://scholarworks.gvsu.edu/sss

Part of the Genetics Commons

\section{ScholarWorks Citation}

Sarkissian, Christina A. and Graham, Douglas H., "Microgeographic Population Genetic Structure of Baylisascaris Procyonis (Nematoda: Ascaroidae) in Western Michigan Indicates the Grand River is a Barrier to Gene Flow" (2014). Student Summer Scholars Manuscripts. 133.

https://scholarworks.gvsu.edu/sss/133

This Open Access is brought to you for free and open access by the Student Summer Scholars at ScholarWorks@GVSU. It has been accepted for inclusion in Student Summer Scholars Manuscripts by an authorized administrator of ScholarWorks@GVSU. For more information, please contact scholarworks@gvsu.edu. 
Microgeographic population genetic structure of Baylisascaris procyonis (Nematoda: Ascaroidae) in Western Michigan indicates the

Grand River is a barrier to gene flow.

Christina A. Sarkissian and Douglas H. Graham

Student Summer Scholar Program - GVSU

2014 


\begin{abstract}
We developed eight polymorphic microsatellites from the parasitic nematode Baylisascaris procyonis. Amplification of these loci in a sample of 74 worms collected from 10 raccoons in Western Michigan revealed significant population structure. Bayesian clustering indicates two subpopulations, one on either side of the Grand River which bisects the region sampled. Estimates of $F_{\mathrm{ST}}$, and results from AMOVA and isolation by distance, further corroborate a scenario whereby the river is acting as a barrier to gene flow, a rather unusual finding given the high vagility of raccoons and microgeographic scale of the analysis. We describe one possible mechanism for how this pattern of structure could have become established.
\end{abstract}




\section{INTRODUCTION}

Baylisascaris procyonis, a.k.a. raccoon roundworm, is a gastrointestinal nematode for which raccoons serve as definitive hosts. They become infected either via the fecal-oral route by ingesting embryonated eggs at latrine sites or by consuming an infected intermediate host. More than 100 animal species, including humans, are known to act as intermediate or 'dead end' hosts, in whose tissues and organs the larval stages of B. procyonis migrate causing debilitating, often fatal disease (Kazacos, 2001). The zoonotic importance of this parasite is increasingly being recognized for its impact on wildlife populations (Page, 2013), zoological gardens (Thompson et al., 2008; Ball et al., 1998), commercial poultry operations (Sorvillo et al., 2002), domestic animals (Rudmann et al., 1996; Kazacos, 2006), and humans (Wise et al., 2005). Given that raccoons adapt well to living in close proximity to humans, and their populations are expanding in size and range in North America (Troyer et al., 2014), as well as in Europe and Asia (Popiolek et al., 2011; Hayama et al., 2007), a better understanding of the population dynamics of B. procyonis would assist public health and wildlife management efforts to control this parasite.

To this end, molecular tools have the potential to greatly improve our understanding of the genetic architecture and microevolution of B. procyonis populations. Ribosomal DNA (rDNA), their internal transcribed spacers (ITS), and mitochondrial cytochrome oxidase genes have provided genetic markers for diagnosis, species discrimination, phylogenetic analysis, and detecting variation between B. procyonis populations (Nadler and Hudspeth, 1998: Nadler and Hudspeth, 2000; Blizzard et al., 2010). However, for the purpose of inferring microevolutionary events, these markers have several limitations. Population genetic inferences based solely on mtDNA can be misleading due to incomplete lineage sorting, introgression via hybridization (Anderson, 2001), and non-neutral evolution (Ballard and Whitlock, 2004). Low polymorphism limits the utility of rDNA, and the presence of variation both within and between repeat arrays can complicate interpretation of ITS sequence data (Vilas et al., 2005). 
Microsatellites by contrast offer a number of advantages, high development cost notwithstanding. These bi-parentally inherited, co-dominant markers consist of small motifs of one to six nucleotides repeated in tandem. They are abundant, often highly polymorphic, easily typed, selectively neutral (but see Haasl and Payseur, 2013), and are well distributed throughout the genome. They have been employed as genetic markers at many scales of analysis_-genome mapping, forensics, parentage analysis, phylogeography — and their high mutation rates make them excellent tools for assaying evolutionary forces acting at the population level (Abdul-Muneer, 2014; Barker, 2002).

The past decade has seen microsatellites developed for the population genetic analysis of a number of parasitic helminth species, e.g. Ascaris lumbricoides (Betson et al., 2014), Schistosoma haematobium (Glenn et al., 2013; Gower et al., 2011), Trichinella spirallis (La Rosa et al., 2012), Fasciola hepatica (Vilas et al., 2012), Dirofilaria immitis (Belanger et al., 2011), Opisthorchis viverrini (Laoprom et al., 2010), Trichostrongylus tenuis (Johnson et al., 2006), Teladorsagia circumcincta and Haemonchus contortus (Silvestre et al., 2009). Our objectives in the current study were to add $B$. procyonis to this list by 1) developing a panel of polymorphic microsatellite markers for this species, and 2) employing these to get a first glimpse of its population structure at a microgeographic level.

\section{MATERIALS AND METHODS}

Worm collection. In the fall of 2012, 74 adult and juvenile specimens of B. procyonis were collected from $\mathrm{a} \sim 500 \mathrm{~km}^{2}$ region in Michigan's lower peninsula bisected by the Grand River (Figure 3). These worms were dissected from euthanized raccoons donated by animal control operations, fur trappers, and from road-kills. They were initially stored in $70 \%$ ethanol at RT, then transferred to individual tubes and kept at $-20 \mathrm{C}$.

DNA extraction. DNA was isolated using the QIAgen DNeasy blood and tissue kit according to the handbook instructions. Concentration and purity were measured using a NanoDrop 2000 
spectrophotometer (Thermo Scientific). Only the anterior 1/10 of each worm was digested in order to avoid, in the case of adult females, contamination from sperm and fertilized eggs (Anderson et al., 2003). Development of microsatellite primers. Two genomic libraries were prepared and enriched for either tetranucleotide $\left[(\mathrm{GATA})_{7},(\mathrm{GATC})_{7}\right.$, and $\left.(\mathrm{GACA})_{7}\right]$ or dinucleotide $\left[(\mathrm{GT})_{12}\right.$ and $\left.(\mathrm{CT})_{12}\right]$ repeats using a microsatellite cloning protocol based on Hamilton et al. (1999) and Hauswaldt \& Glenn (2003), modified as reported earlier (Beheler et al. 2004). The library was constructed using a pooled sample of genomic DNA from two male B. procyonis worms, collected from fresh $(<1 \mathrm{hr}$ old) road-killed raccoons in Northern Indiana, USA. DNA was extracted from the worms using a standard phenol:chloroform extraction procedure (Green and Sambrook, 2012).

A total of 2000 recombinant clones were sequenced and the sequence data were imported into SEQUENCHER 4.1 (Gene Codes Corporation) for analysis. A subset $(n=160)$ of microsatellite-containing sequences was selected, and primers designed for PCR amplification were developed using PRIMER3

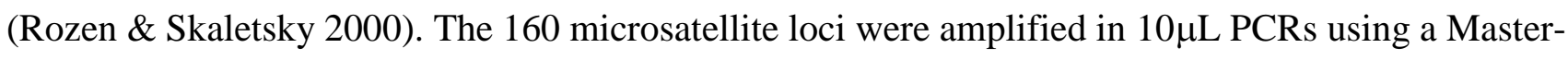
cycler ep gradient (Eppendorf) and $20 \mathrm{ng}$ of template DNA, $0.2 \mathrm{mM}$ of each dNTP, $0.2 \mu \mathrm{M}$ of each primer, $1 \mathrm{U}$ of Taq DNA polymerase (NEB) and $1 \mathrm{X}$ Thermopol reaction buffer (20 mM Tris-HCl, $10 \mathrm{mM}\left(\mathrm{NH}_{4}\right)_{2} \mathrm{SO}_{4}, 10 \mathrm{mM} \mathrm{KCl}, 2 \mathrm{mM} \mathrm{MgSO} 4,0.1 \%$ Triton X-100; NEB). The amplification conditions were as follows: $94{ }^{\circ} \mathrm{C}$ for $2 \mathrm{~min}$, then $94{ }^{\circ} \mathrm{C}$ for $30 \mathrm{~s}$, annealing temperature (Table 1) for $30 \mathrm{~s}, 72{ }^{\circ} \mathrm{C}$ for $30 \mathrm{~s}$ for 35 cycles, then $72{ }^{\circ} \mathrm{C}$ for $10 \mathrm{~min}$ and a final extension at $60{ }^{\circ} \mathrm{C}$ for $45 \mathrm{~min}$. PCR products were initially screened on $2 \%$ agarose gels stained with ethidium bromide to check for positive amplification. A total of 99 of the 160 loci consistently produced products of the expected size and subsequently were screened for polymorphism in a panel of 23 individuals (i.e. a locus would need to have approximately one allele at a frequency of $\geq 98 \%$ to be scored as monomorphic). The protocols for the above polymorphism screening were the same as those given above, except that 1) in each reaction, the concentration of dTTP was reduced to $1.5 \mathrm{mM}$ and $0.5 \mathrm{mM}$ of chromatide rhodamine green $5 \mathrm{dUTP}$ 
(Molecular Probes) was added, and 2) electrophoresis was performed through a 5\% polyacrylamide gel on an ABI 377 automated sequencer (Applied Biosystems). Of the 99 primer sets screened, 8 loci were found to be polymorphic (average allelelic richness: 3.75; Table 1). After optimizing PCR conditions we screened the 8 polymorphic loci using a screening set of 47 individual worms collected from 22 individual raccoons using the protocol outlined above. We calculated observed heterozygosity $\left(H_{\mathrm{O}}\right)$ and expected heterozygosity $\left(H_{\mathrm{E}}\right)$ using the software CERVUS 1.0 (Marshall et al. 1998).

$\underline{P C R}$ amplification. The 5' end of one oligo from each primer pair was ligated with the following universal tag sequence (UTS): 5'-CAGTCGGGCGTCATCA-3'. The choice of whether it was the F or the R primer in each pair that received the UTS was based on which potential combination (i.e. UTS-F and R vs. F and UTS-R) received the highest efficiency rating using NetPrimer (Premiere Biosoft). In addition to the $\mathrm{F}$ and $\mathrm{R}$ primers, each reaction also contained a third oligo consisting of one of the four dyes in Applied Biosystems' Dye Set 33 (6FAM, VIC, NED, and PET) ligated to the 5' end of the UTS. Microsatellite loci were amplified in a reaction volume of $25 \mu$ with Promega's GoTaq ${ }^{\circledR}$ Core System II using $1 \mu \mathrm{l}(\sim 10 \mathrm{ng})$ of DNA template and $1 \mu \mathrm{M}$ of each primer; the quantities of the remaining reactants were per the manufacturer's guidelines. Amplification was carried out using a BioRad T-100 ${ }^{\mathrm{TM}}$ thermal cycler as follows. After $2 \mathrm{~min}$ of initial denaturing at 95C: [95C $30 \mathrm{sec}, 60 \mathrm{C} 1 \mathrm{~min}, 72 \mathrm{C} 1 \mathrm{~min}]$ (x3), [95C $30 \mathrm{sec}, 55 \mathrm{C} 1 \mathrm{~min}, 72 \mathrm{C} 1 \mathrm{~min}$ ] (x30), 72C $10 \mathrm{~min}$, 4C hold. PCR products were screened on $1 \%$ agarose gels stained with ethidium bromide to check for positive amplification. As a quality control step, following genotyping (below), a randomly chosen subset of samples for each locus was reamplified to verify reliability in allele size. The program MICRO-CHECKER (Oosterhout et al. 2004) was used to screen for technical errors that can occur during PCR amplification, such as stuttering, large allele dropout, and null alleles.

Genotyping. Fragment analysis was performed with an ABI 3130xL genetic analyzer (Life Technologies). Alleles were sized in Geneious 7.1.5 (Biomatters) using the LIZ500 size standard. 
Population structure. We used STRUCTURE v. 2.3.4 (Pritchard et al., 2000) to test for evidence of cryptic population structure or physical barriers to dispersal. Structure uses a Markov chain Monte Carlo (MCMC) algorithm to minimize Hardy-Weinberg and linkage disequilibrium within each of $K$ clusters, and generates a probability $Q$ of an individual belonging to each cluster. We used STRUCTURE to calculate the likelihood of the data assuming the entire population was composed of $K=1$ to 10 distinct clusters using a model that assumes admixture and independent allele frequencies. To identify the most likely number of clusters $K$, we performed 5 independent runs for each $K$ with a burn-in value of $10^{5}$ steps followed by $10^{6} \mathrm{MCMC}$ simulations. The most likely $K$ was determined by following the guidelines of Pritchard et al. (2000), and using the second order rate of change in the likelihood distribution, the $\Delta K$ algorithm of Evanno et al. (2005). Output for $\Delta K$ was visualized with Structure Harvester (Earl and vonHoldt, 2012).

Population heterozygosity was assessed by calculating the number of effective alleles $\left(N_{\mathrm{e}}\right)$, mean observed heterozygosity $\left(H_{\mathrm{O}}\right)$, and the mean expected heterozygosity $\left(H_{\mathrm{E}}\right)$ under Hardy-Weinberg equilibrium. Deviation from Hardy-Weinberg equilibrium was assessed at each locus using an exact test as implemented in GENEPOP (Raymond and Rousset, 1995). Hierarchical partitioning of genetic variation among and within infrapopulations, and among regions was performed by AMOVA (Excoffier et al., 1992) as implemented in GENALEX 6.5 (Peakall and Smouse, 2012). Wright's $F$-statistics, as implemented by Weir and Cockerham (1984), were also estimated within the AMOVA framework since it allows for statistical testing. With panmixia $\left(F_{\mathrm{ST}}=0\right)$ as the null hypothesis, to determine whether an observed value of $F_{\mathrm{ST}}$ was significantly greater than that expected by chance, it was compared against the outcomes of 999 random permutations; if the observed value was greater than the permuted value $95 \%$ or more of the time, the results were deemed significant at the $5 \%$ level.

Isolation by distance was tested for all infrapopulations, and separately for those North and those South of the Grand River, using Mantel's test of matrix correspondence (Mantel, 1967) applied to a comparison of all pairwise $F_{\mathrm{ST}} /\left(1-F_{\mathrm{ST}}\right)$ values (Rousset, 1997) with all pairwise log-transformed 
geographic distances. For each comparison (total, North, and South), statistical significance was tested via random permutation, as described above, using GENALEX 6.5.

\section{RESULTS}

We detected 27 alleles at eight microsatellite loci in 74 individual worms. Estimated variability at the eight loci is summarized in Table 2. Allele frequencies at two loci (Bp107 and Bp122) showed slight deviation from Hardy-Weinberg equilibrium; significance on exact tests was $P=0.038$ and 0.044 respectively. There were no null alleles, stuttering errors or evidence of allelic dropout in any of the loci, as analyzed by MICRO-CHECKER.

The results from the Bayesian cluster analysis clearly indicate a subdivision of the population into two genetic groups $(K=2$; Figures 1 and 2$)$. Interestingly, there appears to be very little admixture between groups (Figure 2), and the probability of a given worm's belonging to one or the other inferred cluster corresponds strikingly well to its geography: the two inferred subpopulations lie on either side of the Grand River (Figure 3).

Despite the fine geographic scale of this analysis, population structure was significant at several levels. Our estimate of $F_{\mathrm{ST}}$ for the entire population was $0.176(P=0.001)$. Mean pairwise $F_{\mathrm{ST}}$ values between infrapopulations North of the Grand River was $0.049(P=0.002)$, and for those South of the Grand it was $0.051(P=0.005)$. All pairwise comparisons of $F_{\mathrm{ST}}$ between infrapopulations are shown in Table 3. These values of $F_{\mathrm{ST}}$ are largely consistent with a pattern of structure defined by the river: pairwise comparisons between infrapopulations within regions (i.e. between raccoons on one side of the river or the other) were mostly nonsignificant, whereas comparisons between regions were all significant (Table 3). Of 45 possible pairwise comparisons, only six were inconsistent with this pattern (indicated in grey in Table 3). 
The partitioning of variance in our AMOVA was also consistent with this North—South pattern: genetic differences between infrapopulations accounted for only $4 \%$ of the total variance, whereas differences between regions (North and South) accounted for over five times this amount (21\%; Table 4). Tests of isolation by distance (IBD) tell a similar story. Within each region, significant IBD was detected, whereas between regions, the IBD signal breaks down and is non-significant (Figure 4). Collectively, these results suggest that the Grand River is acting as a barrier to gene flow between sampled populations of B. procyonis to its North and those to the South.

\section{DISCUSSION}

Here we report the development of eight microsatellite markers for B. procyonis, and provide the first description of the population genetics of this species on a local scale. The polymorphism of these markers (mean number of alleles per locus $=3.375$ ) was generally lower than that reported for microsatellites in other parasitic nematodes (e.g. the studies cited in the introduction all report higher mean allele numbers). The observation of reduced microsatellite variability in other organisms has been variously ascribed to low effective population size (Bishop et al., 2009; Hauser et al., 2002); fluctuations in population density (Cimmaruta et al., 2010), low rates of recombination (Payseur and Nachman, 2000), and selection at linked loci (Olafsdottir et al., 2007). The relative influences of these factors in the present study remain to be assessed. Our sample size $(n=74)$ is more than sufficient to estimate allele richness and frequencies (Hale et al., 2012), although the restricted geographic scale of the sampling might possibly impact this; future studies of $B$. procyonis population genetic structure (PGS) on a broader geographic scale will shed light on this.

PGS in parasitic nematodes runs the gamut from panmixia (Grillo et al., 2007; Johnson et al., 2006; Webster et al., 2007) to moderate (Hawdon et al., 2001) to highly structured (Blouin et al., 1999; Redman et al., 2008). This variation is influenced by ecological factors, differences in nematode life 
history, and host biology (Nadler, 1995; Huyse et al., 2005). Nematodes of domestic and companion animals generally exhibit low structure owing to high gene flow resulting from widespread host transport (Blouin et al., 1995; Grillo et al., 2007), whereas in wild host species, factors relating to vagility, territoriality, and ecological barriers will generally determine the degree to which structure is exhibited in their parasite populations. Our results indicate that, at least in the case of Western Michigan, on a microgeographic scale B. procyonis exhibits significant PGS, and that this structure correlates strongly with a physiographic feature, the Grand River. Global $F_{\mathrm{ST}}$ and pairwise values between infrapopulations separated by the Grand River (i.e. between regions, Table 3) were significant—but not among infrapopulations within regions. With a few exceptions highlighted in grey in Table 3, these estimates are consistent with a pattern of gene flow being impeded by the river. IBD and AMOVA results corroborate this.

Although rivers have been implicated as dispersal barriers to raccoons under certain conditions (Smith et al., 2002), their permeability to dispersal varies depending on their width, whether or not they are frozen (Cullingham et al., 2009), and the presence of bridges (Rosatte et al., 2007). The width of the Grand River in our collection area ranges from over 1,000 feet at several points near its mouth to under 200 feet at a number of points East of Grand Rapids (as measured on Google Earth). It is not inconceivable that raccoons might occasionally swim across this; however, it is more likely that they would walk across it during the winter months when it is frozen, as has been observed in other temperate regions (Cullingham et al., 2009).

This seasonal variation in river permeability, if considered in light of annual fluctuations in infection prevalence, may explain the PGS we observed. The prevalence of $B$. procyonis infection among raccoons in our study area shows a pronounced seasonality; it exceeds $70 \%$ during the late spring and fall, and approaches zero during the winter months (data not shown), a pattern also observed in other temperate regions in the U.S. (Kidder et al., 1989; Kazacos, 2001). Whether this is a function of worm life span, self-curing on the part of raccoons, starvation induced by host torpor, or other factors has yet to 
be determined. Each spring, a new generation of $B$. procyonis adults arises, in a manner analogous to the hatching of annual plant seedlings, via infections recruited into the raccoon population from latrine sites (in the case of juveniles) and infected intermediate hosts (in the case of adults). Therefore, the time of year when raccoons are most likely to cross the Grand River is the time when they are least likely to be harboring worms. This would permit gene flow among raccoon populations on either side of the river, but not among populations of $B$. procyonis. Although microsatellites have been developed for the raccoon (Fike et al., 2007), as it was not our initial objective, we did not simultaneously assay genetic structure of the raccoons in this study (i.e. a co-structure analysis sensu Criscione (2008)), the results of which would have informed the above hypothesis. A finding of little or no genetic structure in the raccoon population would lend support to our proposed explanation, whereas significant structure would suggest that the Grand River is a barrier to gene flow for both host and parasite in this particular case.

It is worth noting that the prevalence and distribution of infection among intermediate hosts in this region is unknown. In other regions, larva migrans has been detected in a number of bird species (Evans, 2002), a host category for which a river would not pose a significant dispersal barrier. To the degree that birds in West Michigan are infected with $B$. procyonis, they are not apparently contributing to gene flow across the Grand River.

Future analyses that include additional microsatellite loci and other nuclear and mitochondrial markers will provide useful context for these results. Additionally, the simultaneous assay of raccoon PGS offers the prospect of separating ecological barriers (i.e. the Grand River) from the possible role of host variables (e.g. demographic structure) in shaping the structure of B. procyonis populations in this region. These efforts are ongoing. 


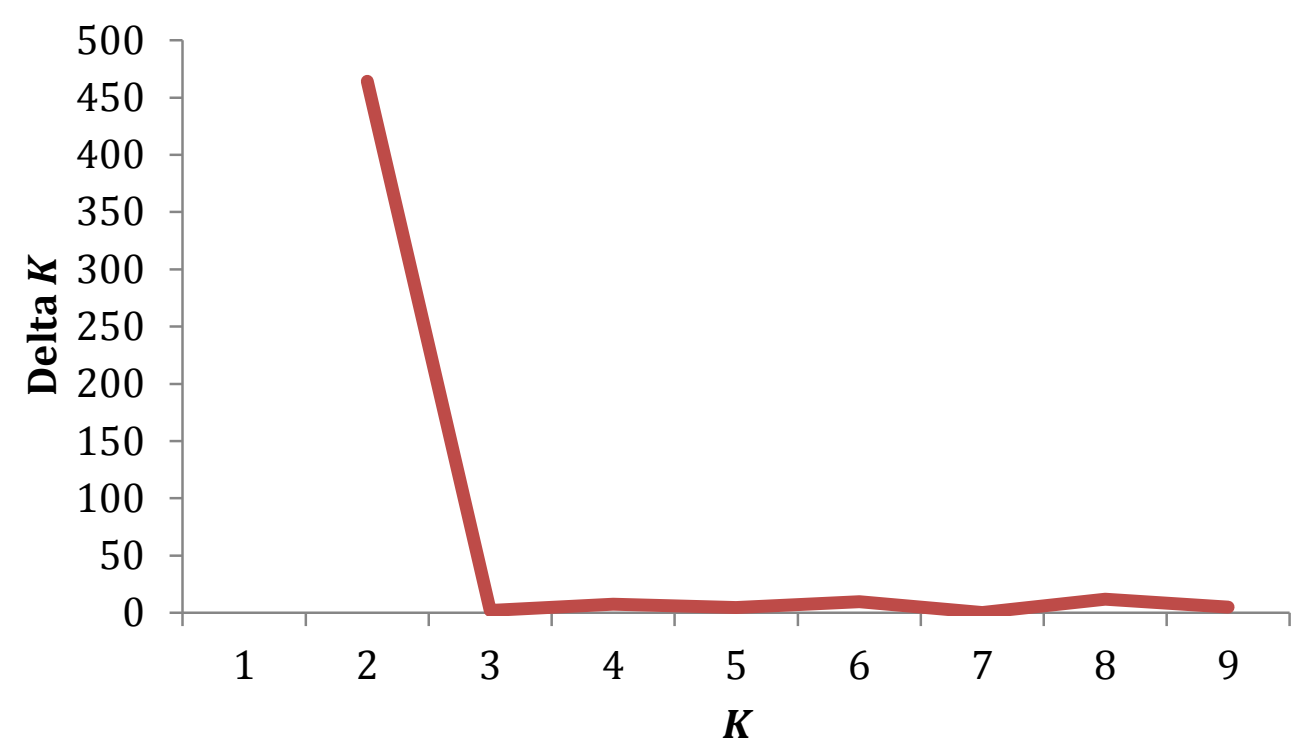

Figure 1. Identification of the best $K$ as inferred by STRUCTURE using the $\Delta \mathrm{K}$ method of Evanno et al. (2005).

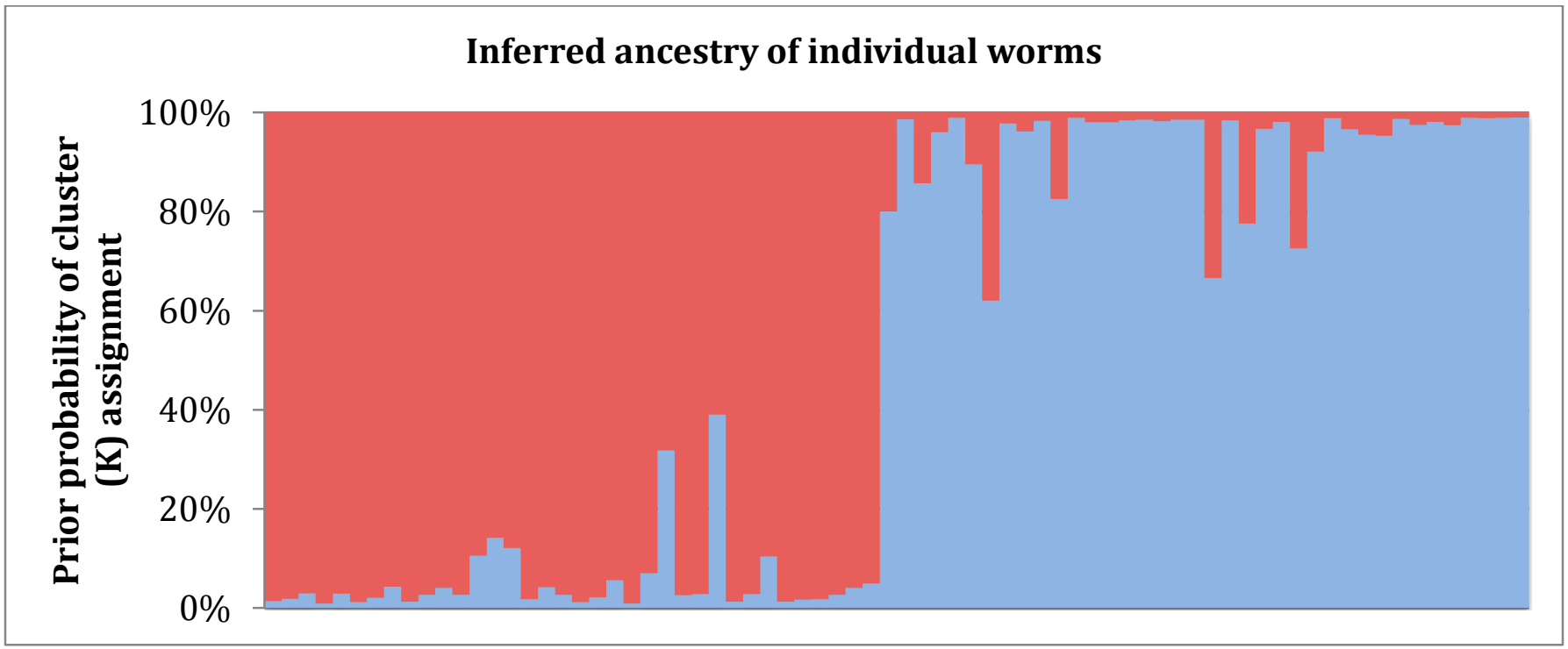

Figure 2. A box plot showing the results of the Bayesian clustering analysis performed by STRUCTURE. Each of the 74 worms is represented by a column partitioned into two colored segments representing the worm's probability of belonging to each of the two inferred genetic clusters. The first 36 columns are from worms collected North of the Grand River (red = North); the remaining 38 samples were collected from South of the Grand River (blue = South). 


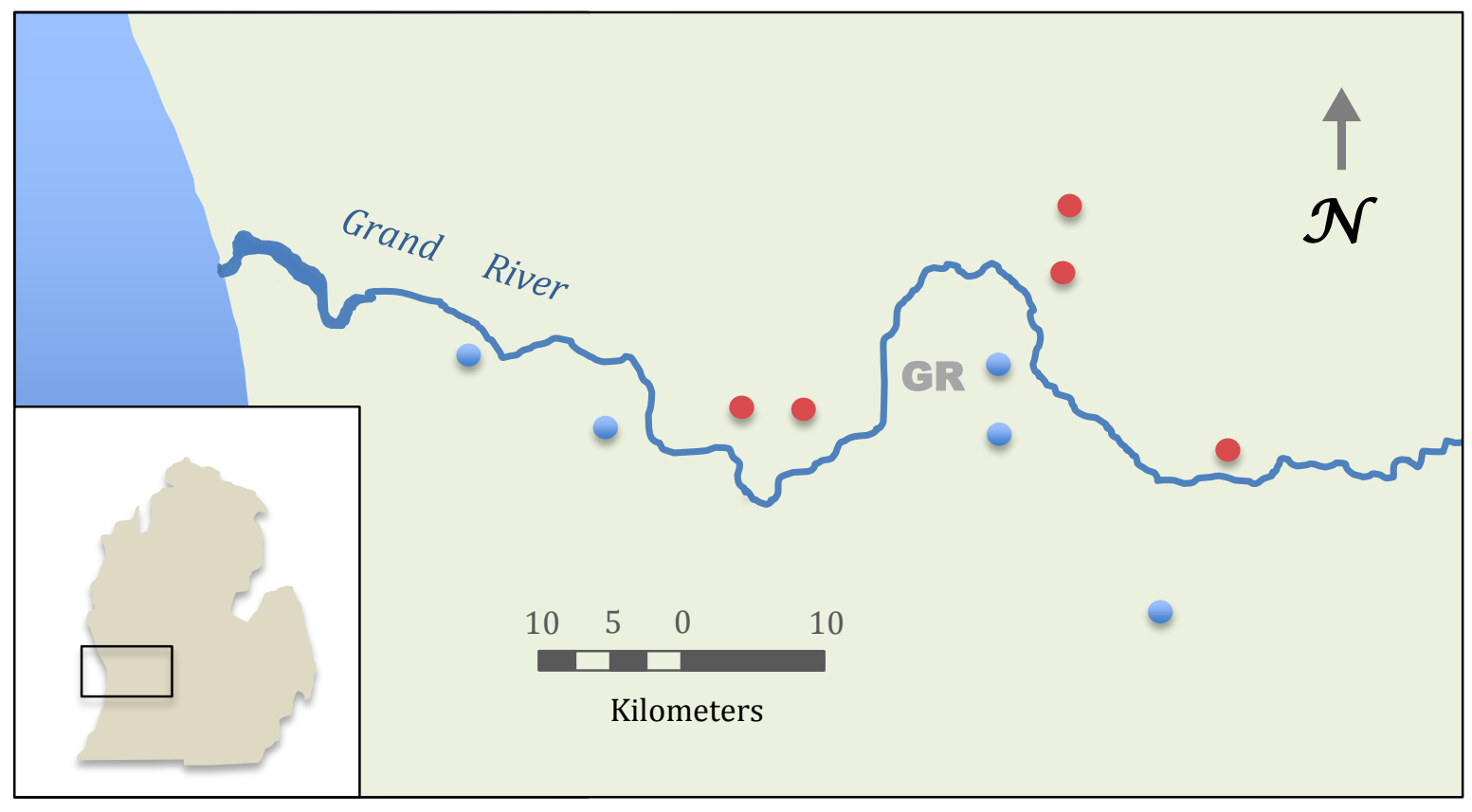

Figure 3. B. procyonis sample collection area in Western Michigan. Points represent the locations where raccoons were collected. Color coding reflects the results of Bayesian cluster analysis; red = North of the Grand River; blue $=$ South of the Grand River. GR = Grand Rapids.
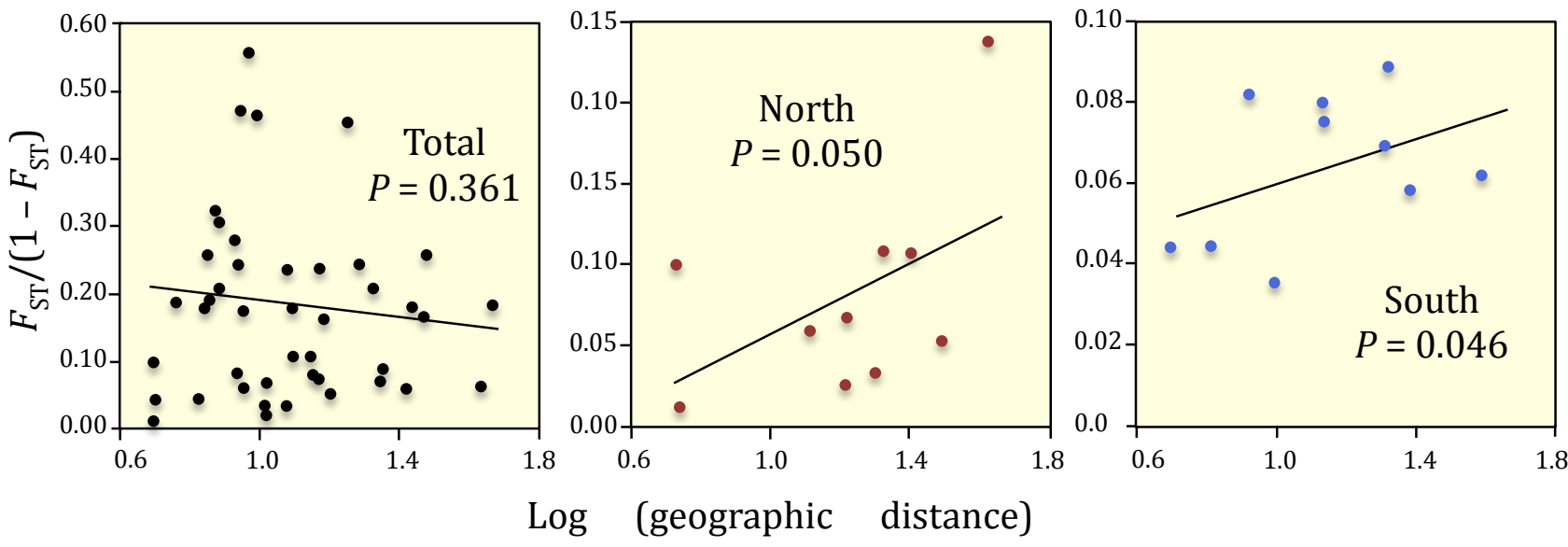

Figure 4. Pairwise geographic distance plotted against genetic distance for all 10 infrapopulations (Total), those North of the Grand River (North), and those South of the Grand River (South). $P$ values refer to the Mantel test of significance $(\alpha=0.05)$ after 999 random permuations. Isolation by distance was detected within each subpopulation (North and South), but not within the total (Total) population. 
Table 1. Characterization of eight polymorphic microsatellite loci developed for Baylisascaris procyonis in a screening set of 47 individual worms. Reported are the numbers of individuals successfully genotyped at each locus $(\mathrm{N})$, the annealing temperature of the primers ( $\mathrm{T}_{\mathrm{M}}$ ) allelic richness $(\mathrm{A})$, as well as the observed $\left(\mathrm{H}_{\mathrm{O}}\right)$ and expected $\left(\mathrm{H}_{\mathrm{E}}\right)$ heterozygosities. No locus deviated significantly from Hardy-Weinberg equilibrium expectations.

\begin{tabular}{|c|c|c|c|c|c|c|c|c|c|}
\hline Locus & $\begin{array}{c}\text { GenBank Accession } \\
\text { Number }\end{array}$ & $\mathbf{N}$ & $\mathbf{T}_{\mathbf{m}}$ & Primer sequence & $\begin{array}{l}\text { Micro- } \\
\text { satellite } \\
\text { motif }\end{array}$ & $\begin{array}{l}\text { Expected } \\
\text { Product } \\
\text { size }\end{array}$ & $\mathbf{A}$ & $\mathbf{H}_{\mathbf{o}}$ & $\mathbf{H}_{\mathbf{e}}$ \\
\hline \multirow[t]{2}{*}{ BP_104 } & -- & 37 & 62.1 & F: AACCTCTGGAATAATCGTTGG & $\mathrm{AC}_{16}$ & 175 & 3 & 0.16 & 0.24 \\
\hline & & & & R: AATTCGACCGGATATGTAAGC & & & & & \\
\hline \multirow[t]{2}{*}{ BP_107 } & -- & 45 & 63.4 & F: TTGACCTTCACGAATATAGGAATG & $\mathrm{AG}_{13}$ & 116 & 5 & 0.33 & 0.62 \\
\hline & & & & R: ATACGCCTCTGGTGGATCTG & & & & & \\
\hline \multirow[t]{2}{*}{ BP_109 } & -- & 45 & 63.3 & F: ATTTGCCCCTTGAAAATTAGG & $\mathrm{AG}_{12}$ & 287 & 4 & 0.24 & 0.47 \\
\hline & & & & R: TGTTCGCATACACTTGCACTC & & & & & \\
\hline \multirow[t]{2}{*}{ BP_114 } & -- & 45 & 60.0 & F: CAATCAATCGCCATGAAG & $\mathrm{CA}_{5} \mathrm{CT}_{25}$ & 130 & 2 & 0.13 & 0.35 \\
\hline & & & & R: TGCAATATCACCTATTCACTCAC & & & & & \\
\hline \multirow[t]{2}{*}{ BP_117 } & -- & 44 & 61.6 & F: GTTCTTCCTCGTTTCCAGTTC & $\mathrm{AG}_{12}$ & 275 & 4 & 0.48 & 0.54 \\
\hline & & & & R: CTTAACGATGAGTACACGATTATAGG & & & & & \\
\hline \multirow[t]{2}{*}{ BP_122 } & -- & 46 & 57.0 & F: AGTTCATTATGCTCTTCAATTC & $\mathrm{AG}_{42}$ & 160 & 3 & 0.17 & 0.56 \\
\hline & & & & R: TGAGAACGCTATATTGATGG & & & & & \\
\hline \multirow[t]{2}{*}{ BP_131 } & -- & 41 & 61.5 & F: ACATAATGAGGGCATCAAATTC & $\mathrm{GT}_{20} \ldots \mathrm{GT}_{4}$ & 190 & 3 & 0.27 & 0.56 \\
\hline & & & & R: TTTCAACAAGTATGATTTCAATGAG & & & & & \\
\hline \multirow[t]{2}{*}{ BP_138 } & -- & 43 & 59.8 & F: TATCTCATTCCTCAGCAGTCTT & $\mathrm{CT}_{18}$ & 112 & 6 & 0.37 & 0.50 \\
\hline & & & & R: TTCGAATGTTCACTGAATAAGAG & & & & & \\
\hline
\end{tabular}


Table 2. Estimated variability at eight microsatellite loci for B. procyonis in Western Michigan. N: number of samples; A: number of alleles; Ne: effective number of alleles, $1 /\left(\right.$ sum of $i$ th allele $\left.{ }^{2}\right) ; H_{\mathrm{O}}$ : observed heterozygosity, $H_{\mathrm{E}}$ : expected heterozygosity; $P$ : exact test probability of departure from Hardy-Weinberg equilibrium $(* p<0.05 ; * * p<0.01$; *** $p<0.001)$.

\begin{tabular}{|c|c|c|c|c|c|c|}
\hline Locus & $\mathbf{N}$ & $\mathbf{A}$ & $\mathbf{N e}$ & $\boldsymbol{H}_{\mathbf{0}}$ & $\boldsymbol{H}_{\mathbf{E}}$ & $\boldsymbol{P}$ \\
\hline Bp104 & 73 & 3 & 1.953 & 0.411 & 0.488 & 0.142 \\
\hline Bp107 & 74 & 3 & 2.343 & 0.432 & 0.573 & $0.038^{*}$ \\
\hline Bp109 & 66 & 3 & 2.833 & 0.727 & 0.647 & 0.170 \\
\hline Bp114 & 74 & 3 & 2.755 & 0.581 & 0.637 & 0.088 \\
\hline Bp117 & 54 & 4 & 3.278 & 0.685 & 0.695 & 0.364 \\
\hline Bp122 & 71 & 4 & 3.442 & 0.521 & 0.709 & $0.044^{*}$ \\
\hline Bp131 & 74 & 4 & 2.223 & 0.689 & 0.550 & 0.126 \\
\hline Bp138 & 74 & 3 & 2.505 & 0.568 & 0.601 & 0.107 \\
\hline Mean & 70 & 3.375 & 2.666 & 0.577 & 0.613 & \\
\hline SE & 2.486 & 0.183 & 0.182 & 0.042 & 0.026 & \\
\hline
\end{tabular}

Table 3. Pairwise comparison of $F_{\mathrm{ST}}$ values between all infrapopulations. R4 $=$ Raccoon 4 , R6 $=$ Raccoon 6 , etc $\ldots$ Red $=$ within-region comparison, North; blue = within-region comparison, South; yellow = between region comparison. Values below diagonal are $F_{\mathrm{ST}}$; those above are $P$ values based on 999 permutations. Values in grey buck expectation at $P=0.05$, see Discussion.

\begin{tabular}{|c|c|c|c|c|c|c|c|c|c|c|c|}
\hline & \multicolumn{5}{|c|}{ North } & \multicolumn{5}{|c|}{ South } \\
\hline & & $\mathrm{R} 4$ & R6 & R8 & R15 & R16 & R3 & R12 & R13 & R9 & R17 \\
\hline \multirow{5}{*}{ North } & $\mathrm{R} 4$ & -- & 0.300 & 0.392 & 0.430 & 0.016 & 0.001 & 0.006 & 0.002 & 0.001 & 0.001 \\
\hline & R6 & 0.032 & -- & 0.165 & 0.327 & 0.114 & 0.001 & 0.005 & 0.001 & 0.001 & 0.001 \\
\hline & $\mathrm{R} 8$ & 0.006 & 0.037 & -- & 0.185 & 0.024 & 0.001 & 0.001 & 0.001 & 0.001 & 0.001 \\
\hline & R15 & 0.000 & 0.008 & 0.018 & -- & 0.005 & 0.001 & 0.001 & 0.001 & 0.001 & 0.001 \\
\hline & R16 & 0.188 & 0.049 & 0.067 & 0.089 & -- & 0.001 & 0.001 & 0.001 & 0.001 & 0.001 \\
\hline \multirow{5}{*}{ South } & R3 & 0.251 & 0.180 & 0.236 & 0.212 & 0.204 & -- & 0.395 & 0.084 & 0.063 & 0.009 \\
\hline & $\mathrm{R} 12$ & 0.264 & 0.154 & 0.290 & 0.219 & 0.205 & 0.003 & -- & 0.086 & 0.047 & 0.163 \\
\hline & R13 & 0.311 & 0.177 & 0.279 & 0.205 & 0.212 & 0.035 & 0.065 & -- & 0.010 & 0.149 \\
\hline & R9 & 0.352 & 0.261 & 0.328 & 0.269 & 0.292 & 0.035 & 0.091 & 0.079 & -- & 0.053 \\
\hline & R17 & 0.365 & 0.246 & 0.337 & 0.249 & 0.281 & 0.074 & 0.045 & 0.028 & 0.056 & -- \\
\hline
\end{tabular}


Table 4. Results of AMOVA.

\begin{tabular}{|l|r|r|r|r|c|}
\hline & \multicolumn{1}{|c|}{ df } & \multicolumn{1}{c|}{ SS } & \multicolumn{1}{c|}{ MS } & Est. Variance & \multicolumn{1}{c|}{$\%$} \\
\hline Among regions & 1 & 48.283 & 48.283 & 0.606 & $21 \%$ \\
\hline Among hosts & 8 & 30.146 & 3.768 & 0.116 & $4 \%$ \\
\hline Within hosts & 136 & 290.845 & 2.139 & 2.139 & $75 \%$ \\
\hline Total & 145 & 369.274 & & 2.860 & $100 \%$ \\
\hline
\end{tabular}




\section{References}

ABDUL-MunEeR PM (2014) Application of Microsatellite Markers in Conservation Genetics and Fisheries Management: Recent Advances in Population Structure Analysis and Conservation Strategies. Gen Res Inter, Article ID 691759

ANDERSON JD, WiLliams-Blangero S, ANDERSON TJC (2003) Spurious genotypes in female nematodes resulting from contamination with male DNA. J Parasitol, 89: $1232-4$

ANDERSON TJC (2001) The dangers of using single locus markers in parasite epidemiology: Ascaris as a case study. Trends Parasitol, 17(4): 183 - 188.

BALLARD JWO AND WHITLOCK MC (2004) The incomplete natural history of mitochondria. MolEcol 13, $729-744$

BALl RL, DRYden M, WiLsOn S, Veatch J (1998) Cerebrospinal nematodiasis in a white-handed gibbon (Hylobates lar) due to Baylisascaris sp. J Zoo Wildl Med. 29: 221-4

BARKER GC (2002) Microsatellite DNA: a tool for population genetic analysis. Trans $R$ Soc Trop Med Hyg, 96 Suppl 1:S21-4

BeHEler AS, FiKe JA, MurfitT LM, Rhodes OE JR, Serfass TS (2004) Development of polymorphic microsatellite loci for North American river otters (Lontra canadensis) and amplification in related Mustelids. Molecular Ecology Notes, 4, 56 - 58.

Belanger DH, Perkins SL, Rockwell RF (2011) Inference of population structure and patterns of gene flow in canine heartworm (Dirofilaria immitis). J Parasitol 97(4): 602-9

Betson M, NejsumP, Bendall RP, Deb RM Stothard JR (2014) Molecular epidemiology of ascariasis: a global perspective on the transmission dynamics of Ascaris in people and pigs. J Infect Dis, 210(6): 932-41

BISHOP JM, LESLIE AJ, BOURQUIN SL, O'RYAN C (2009) Reduced effective population size in an overexploited population of the Nile crocodile (Crocodylus niloticus). Biol Conserv, 142(10): $2335-2341$ 
BlizZARd EL, DAvis CD, Henke S, Long DB, Hall CA, YABSEly MJ (2010) Distribution, prevalence, and genetic characterization of Baylisascaris procyonis in selected areas of Georgia. J Parasitol, 96(6):1128-1133

Blouin MS, Yowell CA, Courtney CH, Dame JB (1995) Host movement and the genetic structure of populations of parasitic nematodes. Genetics, 141: $1007-1014$

BLOUIN MS, LUI J, BARRY RE (1999) Life cycle variation and the genetic structure in nematode populations. Heredity, 83: $253-259$.

Cimmaruta R, Angeletti D, Pontremolesi A, NAscetti G (2010) Low microsatellite variation in Aphanius fasciatus from the Tarquinia Salterns. Transit Waters Bull, 4(2): 83-93

CRISCIONE C. D. (2008) Parasite co-structure: broad and local scale approaches. Parasite 15:439-443

Cullingham, CI, Kyle CJ, Pond BA, ReEs EE, And White BN (2009) Differential permeability of rivers to raccoon gene flow corresponds to rabies incidence in Ontario, Canada. Mol Ecol, 18, 43-53

EARL DA, AND VONHOLDT BM (2012) STRUCTURE HARVESTER: A website and program for visualizing STRUCTURE output and implementing the Evanno method, Conservation Genetics Resources, 4 (2) 359-361.

Evanno G, REGNAut S, AND Goudet J (2005) Detecting the number of clusters of individuals using the software STRUCTURE: a simulation study, Molecular Ecology, 14, 2611 - 2620.

Evans, R (2002) Baylisascaris procyonis (Nematoda: Ascarididae) larva migrans in free-ranging wildlife in Orange County, California. J Parasitol, 88(2): 299 - 301

EXCOFFIER L, SMOUSE P, AND QUATTRO J (1992) Analysis of molecular variance inferred from metric distances among DNA haplotypes: application to human mitochondrial DNA restriction data. Genetics, 131, 479-491

Fike JA, Drauch AM, Beasley JC, Dharmarajan JC, ANd Rhodes OE (2007). Development of 14 multiplexed microsatellite loci for raccoons, Procyon lotor. Mol Ecol Notes, 7: 525 - 527. 
Glenn TC, LAnCe SL, McKee AM, Webster BL, EMERy AM, ZERlotini A, Oliveira G, Rollinson D, FAIRCLOTH BC (2013) Significant variance in genetic diversity among populations of Schistosoma haematobium detected using microsatellite DNA loci from a genome-wide database. Parasit \& Vectors 6:300

Gower CM, Gabrielli AF, SAcko M, Dembelé R, Golan R, EMERy AM, Rollinson D, WebSTER JP (2011) Population genetics of Schistosoma haematobium: development of novel microsatellite markers and their application to schistosomiasis control in Mali. Parasitol 139(7): 962 .

Grillo V, Jackson F, Cabaret J, Gilleard JS (2007) Population genetic analysis of the ovine parasitic nematode Teladorsagia circumcinta and evidence for cryptic species. Inter J Parasitol, 37: 435 447.

GREEN MR AND SAMBROOK J (2012) Molecular cloning: a laboratory manual. Cold Spring Harbor Press HAASL RJ AND PAYSEUR BA (2012) Microsatellites as targets of natural selection. Mol. Biol. Evol. 30(2): $285-298$

HALE ML, BuRG TM, STEEVES TE (2012) Sampling for microsatellite-based population genetic studies: 25 to 30 individuals per population is enough to accurately estimate allele frequencies. PLoS ONE 7(9): e45170

HAmilton MB, Pincus EL, Di FIORE A, Fleischer RC (1999) Universal linker and ligation procedures for construction of genomic DNA libraries enriched for microsatellites. Biotechniques, 27, 500507.

Hauser L, Adcock GJ, Smith PJ, Bernal Ramirez JH, Carvalho GR (2002) Loss of microsatellite diversity and low effective population size in an overexploited population of New Zealand snapper (Pagrus auratus). PNAS, 99(18): 11742-11747

HAUSwALDT SJ, GLENN TC (2003) Microsatellite DNA loci from the diamondback terrapin (Malaclemys terrapin). Molecular Ecology Notes, 3, 174-176. 
HAWDON JM, Li T, ZHAN B, BLOUIN M (2001) Genetic structure of populations of the human hookworm, Necatur americanus, in China. Mol Ecol, 10: 1433 - 1437

HAYAMA H, KANEDA M, TABATA M (2007) Rapid range expansion of the feral raccoon (Procyon lotor) in Kanagawa Prefecture, Japan, and its impact on native organisms, In Koike F, Clout MN, Kawamichi M, De Poorter M and Iwatsuki K (eds), Assessment and Control of Biological Invasion Risks. Shoukadoh Book Sellers, Kyoto, Japan.

HuYse T, POUlin R, AND THERON A (2005) Speciation in parasites: a population genetics approach. Trends in Parasitology, 21(10): 469 - 475.

JoHnson PCD, WeBster LMI, AdAM A, BuCKLAND R, DAwsOn DA, KELLER LF (2006) Abundant variation in microsatellites of the parasitic nematode Trichostrongylus tenuis and linkage to a tandem repeat. Mol Biochem Parasitol, 148: 210 - 218

KAZACOS, K.R. (2006) Unusual fecal parasite in a dog. NAVC Clinician's Brief 4, 37-39

KAZACOS KR (2001) Baylisascaris procyonis and related species. In: Samuel WM, Pybus MJ, Kocan AA, eds. ( $2^{\text {nd }}$ Ed.) Parasitic diseases of wild mammals. Ames: Iowa State University Press. pp 301341.

Kidder JD, WAde SE, Richmond ME, Schwager SJ (1989) Prevalence of patent Baylisascaris procyonis infection in raccoons (Procyon lotor) in Ithaca, New York. Journal of Parasitology 75: $870-874$.

LaOprom N, SithithaWorn P, Ando K, Sithithaworn J, WongKham S, LAHa T, KLinbunga S, WEBSTER JP, ANDREWS RH (2010) Microsatellite loci in the carcinogenic liver fluke, Opisthorchis viverrini and their application as population genetic markers. Infect Genet Evol. 10(1):146-53

La Rosa G, Marucci G, Rosenthal BM, Pozio E (2012) Development of a single larva microsatellite analysis to investigate the population structure of Trichinella spiralis. Infect Genet Evol. 12(2):369-76 
MANTEL N (1967) The detection of disease clustering and a generalized regression approach. Cancer Research 27 (2): 209-220

Marshall TC, Slate J, Kruuk LEB, Pemberton JM (1998) Statistical confidence for likelihood-based paternity inference in natural populations. Molecular Ecology, 7, 639-655.

NADLER S (1995) Microevolution and the genetic structure of parasite populations. J Parasitol 81(3): 395 $-403$

NADLER S AND HUdSPETH D (1998) Ribosomal DNA and phylogeny of the Ascaridoidea (Nemata: Secernentea): implications for morphological evolution and classification. Mol Phyl Evol 10, 221236.

NADLER S AND HudSPeth D (2000) Phylogeny of the Ascaridoidea (Nematoda: Ascaridida) based on three genes and morphology: hypotheses of structural and sequence evolution. J Parasitol (86)2: $380-393$

Olafsdottir GA, SNORRAson SS, Ritchie MG (2007) Parallel evolution? Microsatellite variation of recently isolated marine and freshwater three-spined stickleback. J Fish Biol, 70 (Suppl. A): 125-131 Oosterhout CV, HutChInson WF, WILLS DPM, SHIPLEy PF (2004) MICRO-CHECKER: software for identifying and correcting genotyping errors in microsatellite data. Mol Ecol Notes 4: 535 - 538.

PAGE LK (2013) Parasites and the conservation of small populations: the case of Baylisascaris procyonis. Intl J Parasitol Parasites Wildl, 2:203-10

PAyseur B. A., AND NACHMAn M.W. (2000). Microsatellite variation and recombination rate in the human genome. Genetics 156:1285-1298

PeAKall R And Smouse PE (2012) GenAlEx 6.5: Genetic analysis in Excel. Population genetic software for teaching and research - an update. Molecular Ecology Notes 6, 288-295 


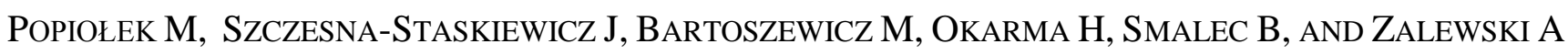
(2011) Helminth parasites of an introduced invasive carnivore species, the raccoon (Procyon lotor L.), from the Warta Mouth National Park (Poland) J Parasitol 97(2): 357-360.

Pritchard JK, SteVens M, And Donnelly P (2000) Inference of Population Structure Using Multilocus Genotype Data, Genetics, 155, 945-959.

RAYMOND M AND ROUSSET F (1995) GENEPOP (version 1.2): population genetics software for exact tests and ecumenicism. $J$ Heredity, 86:248-249

Redman E, Packard E, Grillo V, SMith J, Jackson F, Gilleard JS (2008) Microsatellite analysis reveals marked genetic differentiation between Haemonchus contortus laboratory isolates and provides a rapid system of genetic fingerprinting. Inter J Parasitol, 38: $111-122$

Rosatte R, Sobey K, Donovan D, Allan M, Bruce L, Buchanan T, Davies C (2007) Raccoon density and movements after population reduction to control rabies. J Wildl Manag, 71, 23732378.

ROUSSET F (1997) Genetic differentiation and estimation of gene flow from $F$-Statistics under isolation by distance, Genetics, 145: 1219-1228

ROZEN S, SKALETSKY HJ (2000) PRIMER3. Available at http://frodo.wi.mit.edu/cgibin/primer3/primer3_www.cgi

Rudmann, D.G., KaZacos, K.R., StorandT, S.T., Harris, D.L., Janovitz, E.B., 1996. Baylisascaris procyonis larva migrans in a puppy: a case report and update for the veterinarian. J. Am. Anim. Hosp. Assoc. 32, 73-76.

Silvestre A, Sauve C, Cortet J, Cabaret J (2009) Contrasting genetic structures of two parasitic nematodes, determined on the basis of neutral microsatellite markers and selected anthelmintic resistance markers. Mol Ecol, 18(24): 5086-100

Smith DL, Lucey B, Waller DA, Childs JE, AND Real LA (2002) Predicting the spatial dynamics of rabies epidemics on heterogeneous landscapes, PNAS, 99, 3668-3672. 
Sorvillo F, Ash LR, Berlin OGW, YAtABe J, Degiorgio C, Morse S.A. (2002) Baylisascaris

procyonis: An Emerging Helminthic Zoonosis. Emer Infec Dis 8(4)

Thompson AB, Glover GJ, Postley RC, SeXsmith JL, Hutchison TWS, KaZacos KR (2008)

Baylisascaris procyonis encephalitis in Patagonian conures (Cyanoliseus patagonus), crested screamers (Chauna torquata), and a western Canadian porcupine (Erethizon dorsatum epixanthus) in a Manitoba zoo. Can Vet J. 49(9): 885-888.

Troyer EM, CAmeron-Devitt SE, Sunquist ME, Goswami VR, Oli MK (2014) Survival, recruitment, and population growth rate of an important mesopredator: the Northern raccoon. PLoS ONE, June 5

VILAS R, CRISCIONE C, BLOUIN M (2005) A comparison between mitochondrial DNA and the ribosomal internal transcribed regions in prospecting for cryptic species of platyhelminth parasites, Parasitol $131,839-846$

Vilas R, VASQUEZ-PRIETO S, PANIAGUA E (2012) Contrasting patterns of population genetic structure of Fasciola hepatica from cattle and sheep: implications for the evolution of anthelmintic resistance. Infect Genet Evol 12(1): 45-52

Webster LM, Johnson PCD, AdAm A, MABLE BK, Keller LF (2007) Macrogeographic population structure in a parasitic nematode with avian hosts. Vet Parasitol, 144: 93 - 103.

WEIR BS AND COCKERHAM CC (1984) Estimating $F$-statistics for the analysis of population structure. Evolution, 38, 1358-1370.

WiSE ME, SORVILlo FJ, SHAFIR SC, Ash, LR, BERLIN OG (2005) Severe and fatal central nervous system disease in humans caused by Baylisascaris procyonis, the common roundworm of raccoons: a review of current literature. Microbes Infect, 7, 317-323. 